\title{
Key antecedents and practices for Supply Chain Management adoption in project contexts
}

\begin{abstract}
An adequate identification of antecedents is recognized as fundamental in order to set the basis for connecting the inter-organizational networks in a SCM perspective. This work aims to identify key antecedents of SCM in a project-based environment by using Interpretive Structural Modelling (ISM). This is firstly useful in order to highlight the relationships among the antecedents and to deduce priority for their achievement. The findings provide a hierarchical perspective of the 16 identified antecedents. In particular, three macro-classes of prerequisites were defined: cross-organizational cooperation, rules and procedures - accessibility, and super-ordinate goals. Moreover, results from a longitudinal and illustrative case study are also presented in order to compare the out-coming ISM model with evidence from a success case in the Yacht-building context so offering interesting insights about the implementation process. From a managerial perspective, the proposed model offers a conceptual path for SCM adoption, emphasizing most critical issues that have to be considered and organized in this complex and unpredictable setting.
\end{abstract}

Keywords: SCM antecedents Project-based environmentsInterpretive Structural ModellingCase studyAdoption path

\section{Introduction}

The frequent over-time and over-budget activities and, more widely, the lack of productivity affecting project-based industries have been steadily discussed by academics and practitioners (e.g. Vrijhoef and Koskela, 2000; $\mathrm{Ng}$ et al., 2002). The main causes of such problems have been often identified at the interfaces of different organizations (Xue et al., 2007) and several authors in the last 
decade showed an increased interest about Supply Chain Management (SCM) theories promoting a more efficient division of labour with the objective to improve the project coordination and the cooperation within and across companies (Das, 2006). Despite claimed benefits, SCM practices did not find a stable adoption in a project-based environment (Gadde and Dubois, 2010) so that research needs to pay further attention to supply chain implications in this context (Crespin-Mazet and Ghauri, 2007). Specifically, in order to successfully introduce SCM practices, the identification of context-specific preconditions (antecedents) is essential. The antecedents refer to all the technological, managerial, financial, relational and cultural aspects and capabilities which are necessary to the implementation process and could be visibly influenced by temporariness of the supply chain, the uniqueness of the final product as such as other peculiar features that characterize the project dimension.

A primary importance is also gained by the analysis of the interrelationships among antecedents in the aim to highlight the priorities among SCM prerequisites, thus providing a support to implement SCM practices.

Accordingly to this research direction, Artto et al. (2008) over-stress the context-specificity of requirements that are necessary for a successful introduction of SCM approach in such context, moreover, Stock et al. (2010) state that the difficult implementation of SCM practices can be a consequence of the scarce attention given to the identification of context-specific antecedents.

An adequate identification of antecedents is in fact recognized to set the basis for connecting the inter-organizational networks and therefore to enhance the relationship perspective within and among organizations (Mentzer et al., 2001).

Based on this research gap, the present study aims to propose an Interpretive Structural Modelling (ISM) based methodology that allows to identify key antecedents of SCM in project-based environment, highlighting their interrelationships and deducing priority of their implementation. Then 
results from a longitudinal case study are presented in order to illustrate the experience from a one-off project industry introducing a set of SCM practices with a network of suppliers.

The originality of the present study relies on its attempt to identify a set of prerequisites that promote SCM techniques in one-off project sectors. In so doing, the proposed model also analyses the interconnections of antecedents and innovatively offers a structured conceptual path for SCM adoption, emphasizing most critical issues that have to be considered and organized in this complex and unpredictable setting. Also, in respect to the "SCM Antecedent" stream of literature (Kotzab et al., 2011; Chin-Chun et al., 2014) the work suggests a different perspective of antecedents focusing the analysis on the capabilities (intended as managerial methodologies and technical tool/systems).

The present article is organized as it follows. Section 2 examines previous literature related to project-based SCM. Section 3 raises the research questions of present contribution. Section 4 discusses and motivates the research methodology. Section 5 presents and discusses the model of antecedents and Section 6 highlights the findings from the case study. Finally, conclusions, limitations and future developments of present research are provided in Section 7.

\section{Theoretical background}

Since the 90s, many scholars recognized the importance of SCM to improve the performance of project-based industries (e.g. construction, shipbuilding) at the strategic, tactical and operational levels (Agapiou et al., 1998). The project literature has been characterized by a growing interest about SCM theories and an increased availability of empirical data has highlighted the improvements that can be obtained with such approach (Eriksson, 2010). The powerful pressures from the external environment, as the increasing level of competition between companies and the harsher requirements of clients in terms of cost, time, quality standards and more reliable planning schedule, have in fact lead Projectbased companies to extend the traditional intra-organizational project activities (design and execution) 
to a network of external companies thus making the adoption of a SCM approach more and more important for acceptable project performance.

Despite the rising attention, SCM initiatives still shows a lack of efficacy and only a partial success of implementation in the project environment (Gadde and Dubois, 2010). Traditional SCM models in fact, were developed for a process-centric context and their transposition in project-oriented contexts is not immediate and structured yet (O'Brien et al., 2002). The relevance of implementing SCM practices along the chain in order to generate value for customers has been investigated for a long time in various sectors (Akintoye et al. 2000; Maleki and Cruz-Machado, 2015) and also revisited more recently at the light of lean and green paradigms (Eriksson, P. E., 2010; Duarte and Cruz-Machado, 2015).

Conversely, project industries substantially differ from the stable and continuous supply chains within "goods and service" sectors for a number of specific characteristics: the high complexity and uncertainty in which the production system operates (Fearne and Fowler, 2006); the transitory site configuration managed by temporary supply chain network (Turner and Müller, 2003); the high customer influence on the final product (Pesämaa et al., 2009); the process fragmentation (Baiden et al., 2006); the complex network of stakeholders, which involves multiple organizations and relationships (Xue et al., 2005). These peculiarities together with a number of cultural factors (e.g. Love et al., 2004) jeopardize the management of relationships between the SC members and are charged to be the rooting causes of the failure to replicate the positive experiences from other sectors.

Nevertheless evidence from Project-SCM literature shows that extant contributions did not focus on the antecedents of SCM introduction but rather on relational aspects, such as collaboration in multipartner projects (Dietrich et al., 2010), integrating technologies (Nikas et al., 2007) and trust among project participants (Hartmann and Caerteling, 2010). Moreover previous empirical research contributions, concerning the analysis of SCM antecedents, stemmed only from process-oriented literature and cannot be easily generalized to other contexts. Halldorsson et al. (2007) for example 
identified a number of preconditions, such as trust, long-term collaboration and willingness to share costs and benefits, which can be found in inter-organizational relationships studies. Then, a work by Kotzab et al. (2011) investigated the relationships among SCM antecedents in the automotive sector, discerning between internal, joint or external conditions, and SCM-related processes; this categorization represents the foundation to further explore in details the preconditions of SCM approach, but as underlined by the authors themselves, the classification is still quite generic and does not include all the aspects of SCM implementation (Kotzab et al., 2011).

\section{Research Questions and Objectives}

Despite the specificities of the project environment and the potential benefits of SCM approach in this context, literature still report a lack of research concerning the investigation of SCM antecedents.

Based on the above-mentioned research gap, the following explorative Research Questions can be formulated:

\section{Which are the SCM antecedents in a project-based environment?}

2. How SCM antecedents are interrelated?

3. How can Main Contractors achieve the antecedents to support SCM practices' implementation?

In accordance with the research questions, the present study identifies the antecedents of SCM implementation in the one-off project context, and analyses the interrelationships among antecedents examining the hierarchical levels of SCM antecedents through the development of a conceptual model. Furthermore, the research investigates the antecedents related to the implementation of SCM practice within a specific industrial project environment: the Mega-Yacht shipbuilding. Finally, it proposes an "adoption path" for the antecedents in order to foster a successful implementation of SCM practices.

\section{Research Methodology}


The research framework, depicted in Figure 1, consists of two main phases: the first is aimed at answering the first two research questions, while the second allow us to answer the third one.

In the first phase extant project literature was analysed to investigate the concept of antecedent in the SCM research field, that is characterized by fragmented approaches and a lack of normative homogeneity between constructs (Harland et al., 2006). The review involved a set of 176 peerreviewed articles from main electronic scientific databases (Scopus, Emerald, JStor, IEEE). All the articles dealt with the topic of project-SCM and were screened by content, e.g. using keywords as "antecedent", "prerequisite", "precondition" in order to identify those items that were perceived as relevant to introduce SCM. To evaluate the actual relevance of the variables, the set of antecedents was subject to a qualitative judgment by a panel of experts.

To analyse the interdependencies between the selected antecedents, then to answer the second research question, the Interpretive Structural Modelling (ISM) (Malone, 1975) has been selected as suitable technique. The rationale is to structure the identified antecedents in order to find out the factors that are prerequisite to success and which facilitate the achievement of others. ISM is a method for identifying relationships among specific items, which define a problem or an issue, useful as an aid to individuals and small groups in developing an understanding of complex situations.

ISM is used by various researchers for modelling the relevant variables of several issues in Supply Chain Management (Vendor Management, Risk Management, Reverse Logistics, Supply Chain Integration \& IT Enabled SCM, SC Integration \& IT Enabled SCM, SC Performance Measurement, see Shahabadkar et al., 2012), but such studies do not concern temporary supply chains producing one-off construction projects through repeated reconfiguration of project organizations.

This method is a suitable approach to our problem because it involves a set of interconnected factors through a systematic and efficient process, produces a structured model or graphical representation of the original problem situation that can be effectively communicated to others, and 
finally forces participants to develop a deeper understanding of the meaning and significance our antecedent's list and their relation (Attri et al., 2013). Qualities of ISM methodology in comparison with Analytic Hierarchy Process (AHP) and Analytic Network Process (ANP) are reported also in SCM literature by Thakkar et al. (2008) which present outstanding merits of ISM over others technique. The most relevant contribution is in the ability to deal with hardly-interconnected networks in order to extract following a "causal mode" the hierarchical structure. Thus, hierarchy is not a (apriori) constrain in the modelling process but an output. The structured technique also help users so to capture and elicitate dynamics of complex processes. In this sense, they highlight that it could be even be utilized as a complementary technique to this MCDM approaches.

To successfully obtain an agreement about the complex links between the number of antecedents, a knowledge extraction technique is required to perform the ISM methodology. At this purpose, the Delphi analysis was selected as suitable to identify and explore causal relationships between antecedents through expert opinions (Mitchell and McGoldrick, 1994; Linstone and Turoff, 2002).

----------- Please insert Figure 1 about here

The selected Panel of experts consisted of SCM experts from both the academic and the industrial world. For the purposes of the present study, 12 experts ( 9 from the top management of leading shipbuilding companies and 3 from academia) with a minimum of 16 years of experience in the sector were consulted through directed interview and focus group based on a semi-structured questionnaire. The interviews took place in sequential meetings. The outline of the questionnaire was sent in advance to the interviewees in order to allow them being properly prepared. 
The second research phase consisted in a longitudinal case study within a peculiar industry but highly representative of the one-off project environment: the Mega-Yacht shipbuilding. Data about the SCM implementation project were collected in the period January 2012-August 2013 again through repeated directed interview and focus groups with the Main Contractor and principal Suppliers (during periodical meetings). Finally, triangulation with project documentation was also assessed.

The research purpose of the case study is illustrative and aims at exploring new insights related to the interrelationships between SCM antecedents. The ISM model of SCM antecedents resulting from the first phase of the work was compared with the real experience of a Main Contractor and its network of suppliers and sub-contractors during the implementation of two SCM practices: the standardization of design/construction processes and the introduction of modular components in the vessel areas characterized by low production variability (e.g. hull, engine room, crew accommodation). The investigation of the process introducing these practices represents a contribution for practitioners, as they are related to the realization of an evolved SCM profile in the project context.

The analysis was focused on the process of implementation. In particular, each portion of the SC implementing the SCM practices was investigated in order to describe and analyse the relationships of the Main Contractor toward the other members of the supply chain to finally identify antecedents, their interconnections and related priority for management. This provided the possibility to extend the analysis to a multitude of subjects, including suppliers and sub-contractors.

The choice of the sample company was fundamental, because this stage of research aims at an indepth analysis of the process. The selected Company (Company A) is one of the largest yacht builders in the world, with a turnover that exceeded 1 billion euros in 2012. It pursues the continuous diversification of the final product, with the aim of satisfying the increasingly complex needs expressed by Owners throughout the world. Facilities consist of six shipyards in Italy and over 300.000 square meters of facilities and several after sales points all around the world. The production output is 
composed by semi-custom ( $70 \%$ of the total) and full-custom yachts ( $30 \%$ of the total). In the first case, the size of the yacht ranges from 24 to 60 meters and the final customer can introduce elements of customization within the configuration of interiors and super-structure. In the second case, the size of the yacht exceeds the 60 meters and the final customer is allowed customizing every section of the product, including the shape of the hull. The firm also offers a global after-sale service through a special division which is dedicated to maintenance and warranty activities for yachts of any type or size.

This company represents a benchmark for excellence in terms of customizability and product performance in the yacht industry. Also, the company with suppliers and sub-contractors established the first formalized vertical network of company in the yacht industry, thus representing an excellent and innovative sample for the investigation of SCM-related antecedents.

The period of observation of the case study started during the initial phase of network establishment, in January 2012, and continued after the introduction of SCM practices, until August 2013, so to achieve prolonged engagement and persistent observation in the field (Creswell, 2007). The companies involved include all main production processes of vessel's construction: technical preparation, internal design, electronics, painting, hull and superstructure, piping, HVAC. Moreover, at least two companies for each typology of product have been selected in order to investigate the implementation of SCM practices considering all the perspectives of main actors involved in the industry. More details about companies and single respondents are highlighted in Table 1. 
A within-case analysis was performed (Eisendhart, 1989), comparing the expected patterns of SCM implementation emerging from the ISM model with the examined patterns in the case study. Also, the analysis of the sequence of events concerning the implementation of SCM practices was displayed.

Results have been continuously built on and compared with emergent theory. The relevant literature, in fact, has been enfolded for each SCM building block, addressing the conflicting contributions and discussing similar results (Voss et al., 2002).

\section{First phase: analysis and discussion}

\subsection{Analysis of results}

Following the research framework in fig. 1 and related steps the analysis will go through the next stages: Identification of Antecedents, Analysis of Interdependencies, and Development of the ISM model.

\subsubsection{Identification of antecedents}

Through the literature analysis, a set of 16 antecedents that may enable and enhance SCM implementation in the project environment was identified. Extant project literature (176 peer-reviewed articles) was firstly analysed to investigate the concept of antecedent in the SCM research field since it is characterized by fragmented approaches and a lack of normative homogeneity between constructs (Harland et al., 2006). Once data was collected, the different type of SCM antecedents or analogous definitions available through the literature (i.e. Relational, Strategic Management, Best Practices, Logistics, Organizational, Behaviour, Marketing stream of literature) were analysed by the researchers and homogenized in order to define foundations of the SCM introduction. Two of the four authors analysed and classified, separately and independently, all the papers. Each of them completed a 
classification/coding table for antecedents, discrepancies were resolved in an open discussion with the other authors and a common table was finally compiled.

Table 2 shows the proposed set of antecedents and main references from project literature. It should be noted that a certain level of overlapping is still evident among the variables. This represents a common element throughout the whole SCM literature where multiple perspectives and "a profusion of overlapping terminology and meanings" exist (Croom et al., 2000). Thus a first output of this phase consisted in obtaining a preliminary homogenization and validation of contents (content validity) for the identified antecedents.

--------- Please Insert Table 2 about here

\subsubsection{Analysis of Interdependences}

To describe the relationships among the proposed antecedents, we gathered the opinions of a group of experts about the existence of a relation between any pair of antecedents and the associated direction of the relation (Malone, 1975). The relationships were analysed through four symbols, which denoted the existence and the direction of relationship between different variables:

- D: the antecedent directly influences another.

- $\mathrm{R}$ : the antecedent is reversely influenced by another.

- M: two antecedents mutually influence each other.

- U: two antecedents are unrelated.

Keeping in mind such relationships, we asked the experts to indicate their opinion separately over a series of rounds. The responses were then gathered by the research team and they were re-circulated to the experts until the consensus was reached. Table 3 shows the Structural Self-Interaction Matrix (SSIM) for the 16 antecedent of SCM implementation, according to ISM methodology. We remark that 
consensus was reached after three iterations of the questionnaire, a number that is low enough to ensure the robustness of results (Custer et al., 1999).

Please Insert Table 3 about here

\subsubsection{Development of the ISM model}

In order to build the ISM model, and according to the ISM methodology, the SSIM was converted into the Reachability Matrix (RM) (Table 4), a binary matrix with the following rules of substitutions:

- If the $(i, j)$ entry in the SSIM was $D$, the $(i, j)$ entry in the RM became 1 and the $(j, i)$ entry became 0 .

- If the $(i, j)$ entry in the SSIM was R, the $(i, j)$ entry in the RM became 0 and the $(j, i)$ entry became 1 .

- If the $(i, j)$ entry in the SSIM was M, both the $(i, j)$ and the $(j, i)$ entry in the RM became 1.

- If the (i,j) entry in the SSIM was $U$, both the $(i, j)$ and the $(j, i)$ entry in the RM became 0.

Please Insert Table 4 about here

Usually, in order to identify key elements, the variables are classified into four categories (i.e. autonomous, linkage, dependent and independent) in accordance with their driving and dependence power; since different levels in their values entail different management actions, priorities and likely also timing of implementations. The driving power of a variable (antecedent) represents the total number of variables which it influences, while the dependence power is the total number of variables which it is influenced by.

With this aim in the Final Reachability Matrix (Table 4), the driving and the dependence power of each antecedent is obtained summing the 1 and 0 values for each row and column respectively. Then, 
power levels were used to place the antecedents in a four-quadrants matrix (Mandal and Deshmukh, 1994) where each quadrant is associated with a cluster of variables, as showed in the powerdependence matrix (see Figure 2).

Please Insert Figure 2 about here

The first cluster comprises the "independent" variables, with strong driving power and weak dependence power. It should be noted that, in the out-coming ISM model, "independent" variables have mostly a strategic connotation, for example "commitment of top-management" (variable 2), "commitment of SC participants" (variable 3), and "congruence of objectives" (variable 4). Providing cultural and motivational foundations of the SCM principles, the continuous improvement and enforcement of these variables need to be addressed with priority by managers in order to leverage their wide-ranging influence. An effective and successful control could also reap significant benefits for the entire SCM project and foster the achievement of all other antecedents.

The second cluster involves the "autonomous" variables, which have weak level of both driving and dependence power. They appear disconnected from the model, having few links with other variables.

The third cluster is constituted by the "linkage" variables that show high level of both driving and dependence power. They can lead instability to the system as any change occurring to them will significantly influence other antecedents. A careful management of such factors is needed, when they manifest since this represents a highly critical task. None of the 16 identified antecedents in this study is unstable, which is a good indicator of robustness.

The fourth cluster includes the "dependent" variables, characterized by weak driving power and strong dependence power. They are influenced by most of other variables and they represent the final 
objective of SC participants. Here, "Dependent" variables have mostly an operating connotation as “information sharing" (variable 7) and "adequate working capabilities" (variable 1), trust (variable 6) or long term focus (variable 10). They are highly dependent on how well the overall SCM issue is managed and usually require control by higher hierarchical levels in the organization.

In order to obtain a partition between levels in the ISM hierarchy, the following steps were executed (Warfield, 1974):

- From the final reachability matrix, for each factor, reachability set and antecedent sets are derived. The reachability set consists of the factor itself and the other factor that it may impact, whereas the antecedent set consists of the factor itself and the other factor that may impact it. Thereafter, the intersection of these sets is derived for all the factors and levels of different factor are determined. The factors for which the reachability and the intersection sets are the same occupy the top level in the ISM hierarchy.

- The top-level variable is then discarded from the list and the same process is repeated to find out the factors in the next level.

As an example, Table 5 shows the first iteration of the procedure. It emerges that the top level antecedent is the "sharing of risks and benefits". After all the iterations, a total of 10 levels were identified. These will be used to build the ISM model (See Figure 3).

Please Insert Table 5 about here

\subsection{Discussion}

The structural model of SCM antecedents is represented in Figure 3, which shows the three clusters emerging from the power-dependence matrix (independent, autonomous and dependent) in relation to the ISM process. The graph was obtained by removing the transitivity between the variables to support 
an easier interpretation of the hierarchical relationships among antecedents. The three clusters are also internally consistent in terms of content and they have been labelled adapting the categories proposed by Pinto et al. (1998) on the antecedents of multi-team collaboration.

Please Insert Figure 3 about here

- The first cluster "independent antecedents", labelled as "Super-ordinate Goals" of SC companies, attain an internal strategic orientation toward SCM adoption and report the highest levels of driving power. The model shows that root-causes of SCM initially lie within the organization regarding the will and/or the capability to extend the planning process outside the borders to partners and company borders to other SC players: the commitment of topCommitment of Top management (variable 2) and the strategic planning among SC participants (variable 14) should firstly focus on an internal alignment towards SCM achieving internal integration (variable 8), commitment of SC participants (variable 3) and congruence of players' objectives (variable 4) before to pursue external integration. This result supports previous works by Wong (2012) and by Lambert and Knemeyer (2004), which highlighted the core relevance of internal antecedents in terms of will and capabilities. However, this study shows how this class of variables do not directly impact on the success of SCM implementation rather they represent the basis to assess other functional/preparatory variables. Further antecedents are in fact required to achieve effective SCM, in accordance with the work by Kotzab et al. (2011). Definitely, this first layer of antecedents can be interpreted as a preliminary basing humus in a SCM adoption path. 
For what concerns this first macro-class of SCM antecedents, findings also underline the importance of a strong commitment of SC participants in order to pursue common objectives which is in accordance with Mentzer et al. (2001). The commitment of all SC participants shows as a necessary condition to motivate all the players involved in the process. As an addition, the on-thefield interviews also highlighted that the internal push to SCM should begin from the Main Contractor, as it represents the actor in the $\mathrm{SC}$ with the highest bargaining power and management capabilities.

- The second cluster "autonomous antecedents" concerns "Rules and Procedures - Accessibility". Coherently with the works by Lambert (2004) and Fawcett et al. (2008), the settlement of a SC network requires a clear set of rules and procedures to avoid opportunistic behaviour and minimize information asymmetries. Despite these variables did not achieve high levels of driving power, they constitute drivers that enable the adequateness of working activities and the correctness of rewarding criteria. It is argued that adequate coordination measures such as shared SC performance measurements (variable 15) and SC members selection based on multi-criteria (variable 11) can significantly facilitate the assessment of a reliable and collaborative Supply Network. Also, IT integration (variable 9) constitutes another key element in enforcing the cooperative behaviour between SC members since it improves data availability and supports coordination/collaboration and control activities along the SC (Grover et al., 2002; Chow et al., 2012). At the light of these evidences, "Rules and Procedures - Accessibility" variables constitute a second level of antecedents which should be treated with priority in a proper SCM adoption path.

- The third cluster, as previously stated, is empty.

- The fourth cluster "dependent antecedents" is about "Cross-organizational Cooperation". This cluster is based on collaborative variables (i.e. foundations of collaboration), such as trust (variable 16), long-term focus (variable 10), relational behaviour (variable 11) and adequate working 
capabilities (variable 1), but it also includes sharing values as such as information sharing (variable 7) and risk-benefit sharing (variable 13). All of them collected a great interest from academia in the last decade literature (e.g. Gadde and Dubois, 2010; Khalfan et al., 2007) where are denoted as the grounding elements to achieve SCM introduction. However, as showed by the ISM model, the cluster has to be interpreted just as the last layer of antecedents in a SCM adoption path.

As highlighted by Chen and Paulraj (2004), a proper information exchange and the establishment of a risk- and benefit-sharing perspective are crucial to enhance SCM. These variables are reported at the top level of the ISM model and classified as "dependent" in the power-dependence matrix. Specifically, the risk- and benefit-sharing with other SC participants constitute the ultimate factor to achieve SCM implementation. This means, primarily, to identify and assess SCM risks, their timing and responsibility, i.e. at which organizational level risk factor rises and related responsibility in order to consent a successful treatment (Aloini et al., 2012). In a second instance, out coming SCM benefits should be shared with the other SC players (Tommelein et al., 2003). This also implies that relevant and potential critical information has to be diffused among a multitude of companies involved in the network consistently and in a continuous and progressive manner over time. Consequently, other basing antecedents such as trust, long-term focus, relational behaviour and adequate working capabilities (variable 1) play a central role for the process' success.

Finally, SCM adoption represents an intensive investment in terms of financial and labour resources which can also expose company processes and products to a number of internal and external risks. Two isolated antecedents emerged from the analysis: contractual protection (variable 5) and funds availability (variable 6). They achieved the lowest levels of both driving and dependence power and seem also conceptually autonomous from other SCM antecedents. Hence, they represent two exogenous contextual variables that may affect the SCM adoption path, but often relying upon 
government regulations and the conditions of financial institutions, with a scarce controllability by SC members.

\section{Second phase: case study analysis and discussion}

The experience of a leading company in the shipbuilding sector (Company A) was analysed while implementing SCM practices with a network of selected suppliers and sub-contractors (here following A.Net); this is in order to compare the results of the ISM model with evidences from a success case. To facilitate discussion and comparison between the ISM conceptual model and the case study, findings are here structured in accordance with the 3 macro-classes of antecedents emerging from the ISM procedure (see Phase 1). Nevertheless, figure 4 also reports the actual chronological schedule of project activities and highlights timing of the antecedent introduction coherently with the milestones of the SCM implementation project. These milestones have been defined and updated every two months in correspondence of the A.Net meetings that occurred in the observed period (December 2011-August 2013).

------- Please Insert Figure 6 about here

\subsection{Super-ordinate Goals}

At the end of 2011, Top-management of Company A decided with high priority to increase the level of SC integration with major suppliers and sub-contractors in order to improve the long-term performance by leveraging on a systematic, strategic coordination of business functions across company borders. With this purpose, an innovative project aiming at introducing SCM practices in the network was officially launched. Achieving and communicating a full commitment by the top- 
management (variable 2) was the first step setting the basis for SCM introduction. This resulted in a direct involvement of top and middle management both in the project promotion and in the preliminary network assessment activities with the potential A.Net partners.

The companies involved in the implementation of initial SCM practices already had repetitive interactions with the Main Contractor and demonstrated excellent design and operational skills. However, these relationships were mainly transactional and continuously re-arranged for every new project, similarly to the relationships with occasional suppliers. To select the players to be officially included in the new network, the Main Contractor has firstly evaluated the ability of participants to plan and implement strategic directions (variable 14). Then, the process has taken into consideration the past collaboration experience of Company A but it has also gone through formal meetings and focus groups finalized to investigate suppliers' interest about the initiative. Only players demonstrating particular willingness and a strong commitment (variable 3) toward a higher SC integration were selected.

As an addition, the preliminary achievement of internal integration (variable 8) was judged fundamental to reduce resistance to changes during the introduction of practices. Thus, the Main Contractor has performed an internal assessment meeting among the various directors of functions and project managers to identify a priority list of business improvements that could have been achieved through increasing levels of SCM integration. They also listed internal process improvements to be achieved in order to enable the Main Contractor external integration (opening processes to Network's participants in a SCM perspective); that was a first action plan for the SCM introduction project.

After that, also companies selected for the A.Net have independently identified a set of common objectives (variable 4), proposing the deliverables and the schedule for the SCM implementation process, which were discussed with the Main Contractor (Company A). Most relevant objectives consisted in a $20 \%$ reduction of design and construction costs for the yacht zones with low variability. 
To achieve these objectives, network participants proposed to define process standards and to introduce modular systems. In a second moment, inputs from a number of sub-contractors lead to the proposals of improving the support for project information exchange and developing IT interfaces between project players. Particularly, the inputs came from the electrical and the HVAC companies being also active in other process-based industries with greater experience on process integration and SC relationships. In a later meeting, A.Net participants detailed the objectives with operational requirements, related milestones and resource requirements. Finally, the objectives were formalized in a formal network contract, thus providing a legal official status to the A.Net for the implementation of SCM practices.

\subsection{Rules and Procedures - Accessibility}

Soon after the preliminary "Assessment of the Supply Network" (see Figure 4), participants agreed to be evaluated by a set of common performance measures (variable 15) finalized to increase their SCM orientation. The bi-monthly evaluation meetings were also an opportunity to review the progress of the A.Net activities and to define the developments to be accomplished by the next one. Accordingly to their requests, suppliers were required to propose a range of possible modular components in order to improve the integration between processes: an example is the case of furniture such as port-holes, handrails, windows with the electrical and the HVAC systems of the engine room. Another important activity was related to the homogenization of the level of detail of the numerous project drawings, the different formats and contents of the specifications which was a first step in order to standardize project documentation.

The definition of shared SC performance measures (variable 15) and the transparency in communication of the criteria for the allocation of the activities among the suppliers (variable 12) have largely stimulated the suppliers' participation to the progress of project activities. This also sought to overcome the solely focus on cost that characterized the relationships in the sector by extending the 
evaluation to other critical dimensions of project success such as labour flexibility, responsiveness to the needs of production, respect for delivery times. As an addition, network participants developed shared procedures for the provision of post-sale services, ranging from management of operations to security and behavioural standards.

Simultaneously with the "Assessment of the Network Control System" and the "Standardization Process", an "IT Integration" project was also launched (see Figure 4): network participants started to identify a set of tools for external IT integration (variable 9). The exchange of project documents among the suppliers, in fact, was traditionally relied on paper-based communications, characterized by a high information lead-time that often was not compatible with the variability of production process. Moreover, the exclusive use of e-mail based communications, frequently adopted in the design stage for sharing the project drawings, limited the visibility and traceability of information. Thus, an External Web Application (WEA) was developed and implemented. By the WEA, the project files become always visible and accessible to selected recipients, avoiding the hassle of e-mail communication and significantly reducing the information lead-time for the acceptance and editing activities. Communications are also recorded and indexed, enhancing the tracking of various information exchanges and fostering accountability. The IT platform can also support a daily update of the work progress through the introduction of 3-D applications which represent a revolution for the hand-crafted construction activities (e.g. painting) traditionally estimated with high approximation so that requiring an intensive day-by-day control. As just an example, during construction activities the production supervisors can be equipped with on-board mobile device providing detailed and updated project documents and drawings, thus reducing the number of RfPI (Request for Project Information). These devices can be also adopted during the post-sale activities, such as for maintenance activities.

To conclude enhancing the support for information sharing and reducing the differences (in terms of both process and documentation standards) between the various technical departments within the 
network, the WEA provided the technological basis for a successful implementation of SCM practices. These factors, in fact, revealed as fundamental requirements for an effective and integrated network control and for the achievement of efficient project collaboration.

\subsection{Inter-organizational Cooperation}

The overall increased transparency in communication and suppliers' selection criteria allowed to better align the capabilities of project players to the objectives of Main Contractor and to enhance the relationships (variable 11) among network participants. Definitely, relationships were also enforced by the adoption of shared IT tools by generating a lock-in mechanism between suppliers and Main Contractor, reducing the occurrence of opportunistic behaviours and encouraging the development of more permanent SC structures with a long-term focus (variable 10).

Moreover, to support the network participants in achieving adequate working capabilities (variable 1) and finally realizing the required performance, training courses have been set up at both the strategic (e.g. project management) and the tactical/operational level (e.g. quality control and reporting). Training activities have been co-financed by the Main Contractor who shared the content of its own internal processes to the other network members. Courses have supported players in reducing capability/skill gaps and facilitated the development of trust-based relationships (variable 16) between the participants.

The improved working capability together with the new emerging long term focus and trust contributed to enlarge information sharing (variable 7) at both operational and design level. E.g. the Main Contractor has started to exchange project files with suppliers of different systems through the WEA.

Finally, in order to effectively introduce SCM practices, network participants have paid a lot of attention to convert the common objectives into shared risks and benefits (variable 13). With this aim, 
in the last phase of the project, Main Contractor's effort was directed to define adequate "Incentives and Rewarding Systems" (see figure 4). Cost reductions obtained by the implementation of SCM practices are in some cases experienced only by the Main Contractor directly, but not by the other network participants which may also presume an overall reduction of profits (e.g. when agreements assess that the work is paid according to the number of worked hours). As an addition, the increase of productivity involving the design offices and the decreased number of reworks could paradoxically negatively affect turnover of suppliers and sub-contractors, hence also their commitment to the project. To avoid such an undesirable phenomenon, the Main Contractor increased the wage of direct worklabour by $5 \%$, thus to explicitly remunerate the efforts for developing standards and modules. As an addition, incentives to SCM practices adoption and sharing of benefits have also involved the procurement process, as the Main Contractor has allowed suppliers and sub-contractors using its frameagreements with major suppliers of materials thus obtaining higher discount rate. This practice enabled suppliers to increase the profit margin due to the lower cost of purchased materials; moreover, the resulting pooling of purchasing also reduced the risk of material shortages in the next production phase.

\subsection{Experienced and expected operational benefits of SCM adoption}

The companies of the network (A.Net), in accordance to the emergent SCM adoption path, have successfully introduced a number of selected SCM practices and also experienced large operational benefits due to the increased integration. Standardization of coordination and manufacturing activities, modularity in system design, Postponement and Spatial integration were assessed in order to obtain a "customized leagile SC" which is oriented towards the increase of productivity and the reduction of reworks and waste. In this aim, the Principal Contractor also reduced the number of critical suppliers with long-term perspective and augmented the level of process formalization and centralization.

Main experienced benefits can be summarized as follows: 
- an increased customer responsiveness resulting from shorter time-to-react and information leadtime which were recognized by the SCM players as the most effective improvement to achieve project success

- a 20\% reduction of design and construction costs for the yacht zones with low variability which is also due to the improved completeness of engineering design and of material requirements

- enhanced quality of operations, due to the reduced number of reworks and the faster approval of consistent design solutions. Poor quality of construction systems traditionally generated claims and disputes between project participants that resulted in schedule delays. After the introduction of SCM practices, the number of reworks decreased by $15 \%$ and the cycle time for the approval of design drawings reduced by $80 \%$

- improved cooperation and coordination with others SC players. Besides the implementation of the investigated practices, the effective introduction of SCM antecedents have allowed achieving a better alignment of objectives and higher cooperation between the various project participants, fostering the implementation extension to other SCM practices in the near future

The here reported preliminary advantages, i.e. enhanced productivity, reactivity and flexibility in the project execution phases, have also expected wide-spread implications on internal and external project performance (i.e. improved overall saturation of resources, higher productivity and thus minor completation time and production costs).

\section{Conclusion}

Project-based industries are often affected by high SC fragmentation, scarce collaboration, and frequent disputes among the extensive networks of suppliers and subcontractors. These problems 
mostly originated at the interfaces with other members of the supply chain, but the implementation of SCM practices appears still difficult and challenging for both practitioners and researchers. This work investigates antecedents of SCM introduction in a project environment. The main contribution is to systematically structure the relationships among the identified SCM antecedents and to compare the out-coming model with evidence from a success case in the Yacht-building context so offering interesting insights about the implementation process.

By the ISM, a set of 16 antecedents have been isolated from the literature, interdependencies analysed and tested to evaluate their practical relevance. Three clusters finally emerge setting the way towards a potential SCM adoption path. The independent connotation of "Super-ordinate goals" emphasizes the criticality to achieve commitment and common objectives among project participants, motivating and driving the introduction of the SCM practices. The autonomous factors included in the "Rules and procedures - Accessibility" cluster represent the formal and technological basis to achieve the dependent antecedents within the "Cross-organizational cooperation" cluster. Finally, "Crossorganizational cooperation" stresses the importance of sharing of risks and benefits between SC participants as the final (dependent) antecedent to successfully implement SCM practices.

The longitudinal case study illustrates a concrete and successful application of the adoption path coherently with the ISM model. Thus, findings enables the empirical explanation of theoretical propositions of the model and also support an own epistemological and generalizable value for replication (Yin, 2003).

The companies of the network, in accordance to the emergent adoption path, have in fact successfully introduced the selected SCM practices and experienced large benefits due to the increased SCM integration: an increased customer responsiveness resulting from shorter time-to-react and information lead-time has been gained and recognized as the most effective improvement to achieve project success. The Main Contractor also reported enhanced quality of operations, due to the reduced 
number of reworks and the faster approval of consistent design solutions. Poor quality of construction systems traditionally generated claims and disputes between project participants that resulted in schedule delays. After the introduction of SCM practices, the number of reworks decreased by $15 \%$ and the cycle time for the approval of design drawings reduced by $80 \%$.

Besides the implementation of the investigated practices, the effective introduction of SCM antecedents have allowed achieving a better alignment of objectives and higher cooperation between the various project participants, fostering the implementation extension to other SCM practices in the near future.

The proposed model, as a structured adoption path, can support managers during the complex and resource-intensive process of $\mathrm{SCM}$ introduction. It can act as a guide to the top management as provides some valuable insights about the interdependencies and the hierarchy of actions to be taken for effective SCM introduction. Moreover, the model can facilitate the understanding of the complex dependencies among antecedents. As an addition, the case study also has a replication-value: managers can get inspiration from the successful experience of the Main Contractor described in the longitudinal case study, when attempting to introduce SCM techniques and tools.

Of course the present article has some limitations. First of all, the proposed model of antecedents was based on the opinion of experts from leading shipbuilding companies and academics. Whether the identified antecedents have a wide-ranging applicability and a similar importance in other project-based supply chains can be assumed, we should be cautious about generalizing our findings to similar industries which production is organized on project basis due to the specificity of the yacht-building industry.

Secondly, limitations can be found in the potential bias arising from the semi-structured interviews of the case study. The limited sample, in fact, can give rise to subjective and expert errors. At this purpose, in order to obtain reliable results, present research attempted to study the research problem 
from a multiple perspective using a mixed research strategy and adoption strict selection criteria for selecting experts

Following main limitations, further investigation and replication of this research is called in order to test and extend proposed findings. The first research direction could be aimed at exploring the generalizability of results in other project-based industries, such as construction, investigating possible commonalities and/or differences. A second direction could be aimed at an in-depth analysis of causeeffect relationships between antecedents. Findings shows that the achievement of antecedents generated self-reinforcing mechanisms between the three clusters of variables: the sharing of risks and benefits fostered increasing commitment toward SCM implementation and toward increased IT integration. These relationships were rarely made explicit in the literature, with a lack of empirical evidence. Further research could be directed to the testing of specific hypotheses that investigate self-reinforcing mechanisms also by means of quantitative methodologies, such as Structural Equation Modelling based on questionnaire survey.

\section{References}

Agapiou, A., Flanagan, R., Norman, G., Notman, D., 1998. The changing role of builders merchants in the construction supply chain. Construction Management \& Economics, 16 (3), 351-361.

Ahuja, V., Yang, J., Shankar, R., 2009. Benefits of collaborative ICT adoption for building project management. Construction Innovation: Information, Process, Management, 9 (3), 323-340.

Akintoye, A., McIntosh, G., Fitzgerald, E., 2000. A survey of supply chain collaboration and management in the UK construction industry. European Journal of Purchasing \& Supply Management, 6, 159-168. 
Aloini, D., Dulmin, R., Mininno, V., Ponticelli, S., 2012. Supply chain management: a review of implementation risks in the construction industry. Business Process Management Journal, 18 (5), 735 761.

Artto, K., Kujala, J., Dietrich, P., Martinsuo, M., 2008. What is project strategy?. International Journal of Project Management, 26, 4-12.

Attri, R., Dev, N., Sharma, V., 2013. Interpretive Structural Modelling (ISM) approach: An Overview. Research Journal of Management Sciences, 2 (2), 3-8.

Baiden, B. K., Price, A. D. F., Dainty, A. R. J., 2006. The extent of team integration within construction projects. International Journal of Project Management, 24 (1), 13-23.

Beath, C.M., 1991. Supporting the information technology champion. MIS Quarterly, 15 (3), 355372.

Biedenbach, T., Müller, R., 2012. Absorptive, innovative and adaptive capabilities and their impact on project and project portfolio performance. International Journal of Project Management, 30 5, 621635.

Brady, T., Davies, A., 2004. Building project capabilities: from exploratory to exploitative learning. Organizational Studies, 25 (9), 1601-1621.

Bredin, K., 2008. People capability of project-based organisations: A conceptual framework. International Journal of Project Management, 26 (5), 566-576.

Briscoe, G., Dainty, A.R.J., Millett, S., 2001. Construction supply chain partnerships: skills, knowledge and attitudinal requirements. European Journal of Purchasing \& Supply Management, 7, 243-255.

Burgess, R., Turner, S., 2000. Seven key features for creating and sustaining commitment. International Journal of Project Management, 18 (4), 225-233. 
Chen, W. T., Chen, T.-T., 2007. Critical success factors for construction partnering in Taiwan. International Journal of Project Management, 25 (5), 475-484.

Chen, H. L., 2011. An empirical examination of project contractors' supply- chain cash flow performance and owners' payment patterns. International Journal of Project Management, 29 (5), 604614.

Cheng, M., Tsai, H., Sudjono, E., 2011. Evaluating subcontractor performance using evolutionary fuzzy hybrid neural network. International Journal of Project Management, 29 (3), 349-356.

Chin-Chun Hsu Keah Choon Tan Tritos Laosirihongthong, 2014. Antecedents of SCM practices in ASEAN automotive industry. The International Journal of Logistics Management, 25 (2), 334 - 357.

Chow, P.T., Cheung, S.O., Chan, K.Y., 2012. Trust-building in construction contracting: Mechanism and expectation, International Journal of Project Management, 30 (8), 927-937.

Creswell, J. W., 2007, Qualitative Inquiry and Research Design, Sage Publications, Pearson, NJ.

Custer, R.L., Scarcella, J. A., Stewart, B.R., 1999. The modified Delphi technique: A rotational modification. Journal of Vocational and Technical Education, 15 (2), 1-10.

Das, A., Narasimhan, R., Talluri, S., 2006. Supplier integration—finding an optimal configuration. Journal of Operations Management, 24 (5), 563-582.

Dietrich, P., Eskerod, P., Dalcher, D., Sandhawalia, B., 2010. The dynamics of collaboration in multipartner projects, Project Management Journal, 41, 59-78.

Duarte, S., and Cruz-Machado, V. 2015. Investigating lean and green supply chain linkages through a balanced scorecard framework, International Journal of Management Science and Engineering Management, 10 (1), 20-29.

Edum-Fotwe, F. T., Thorpe, A., McCaffer, R., 2001. Information procurement practices of key actors in construction supply chains. European Journal of Purchasing and Supply Management, 7 (3), $155-164$. 
Eisendhart, K. M., 1989. Building theory from case study research”, Academy of Management Review, 14 (4), 93-138.

Ekström, M.A., Björnsson, H.C., Nass, C.I., 2003. Accounting for rater credibility when evaluating AEC subcontractors. Construction Management and Economics, 21 (2), 197-208.

Eriksson, P. E., Nilsson, T., Atkin, B., 2008. Client perceptions of barriers to partnering. Engineering. Construction and Architectural Management, 15 (6), 527-539.

Eriksson, P. E., 2010. Improving construction supply chain collaboration and performance: a lean construction pilot project. Supply Chain Management: An International Journal, 15 (5), 394-403.

Eriksson, P. E., 2012. Exploration and exploitation in project-based organization and diffusion of knowledge at different organizational levels in construction companies. International Journal of Project Management, In press.

Errasti, A., Beach, R., Oyarbide, A., Santos, J., 2007. A process for developing partnerships with subcontractors in the construction industry: An empirical study. International Journal of Project Management, 25, 250-256.

Errasti, A., Beach, R., Oduoza, C., Apaolaza, U., 2009. Close coupling value chain functions to improve subcontractor manufacturing performance. International Journal of Project Management, 27, 261-269.

Froese, T.M., 2010. The impact of emerging information technology on project management for construction. Automation in Construction, 19, 531-538.

Gadde, L. E., Dubois, A., 2010. Partnering in the construction industry - Problems and opportunities. Journal of Purchasing and Supply Management, 16 (4), 254-263.

Grover, V., Teng, J., Fiedler, K., 2002. Investigating the role of information technology in building buyer-supplier relationships. Journal of the Association for Information Systems, 3, 217-245. 
Gunasekaran, A, Love, P.E.D., 1998. Concurrent engineering a multi-disciplinary approach for construction. Logistic Information Managent, 11 (5), 295-300.

Guth, W.D., Macmillan, I.C., 1986. Strategy implementation versus middle management selfinterest. Strategic Management Journal, 7, 313-327.

Halldorsson, A., Kotzab, H., Mikkola, J.H. and Skjøtt-Larsen, T., 2007. Complementary theories to supply chain management. Supply Chain Management: An International Journal, 12 (4), 284-96.

Harland, C.M., Lamming, R.C., Walker, H., Phillips, W.E., Caldwell, N.D., Johnsen, T.E., Knight, L.A., Zheng, J., 2006. Supply management: is it a discipline?. International Journal of Operations \& Production Management, 26 (7), $730-753$.

Hartmann, A., Caerteling, J., 2010. Subcontractor procurement in construction: the interplay of price and trust. Supply Chain Management: An International Journal, 15 (5), 354-362.

Hsu, J.S., Liang, T.P., Wu, S.P.J., Klein, G., Jiang, J.J., 2011. Promoting the integration of users and developers to achieve a collective mind through the screening of information system projects. International Journal of Project Management, 29 (5), 514-524.

Ingirige, B., Sexton, M., 2006. Alliances in construction: Investigating initiatives and barriers for long-term collaboration. Engineering, Construction and Architectural Management, 13 (5), 521-535.

Kadefors, A., 2004. Trust in project relationships-inside the black box. International Journal of Project Management, $22(3), 175-182$.

Khalfan, M.M.A., Anumba, C.J., Siemieniuch, C.E., Sinclair, M.A., 2001. Readiness Assessment of the construction supply chain for concurrent engineering. European Journal of Purchasing \& Supply Management, 7, 141-153.

Khalfan, M.M.A., McDermott, P., Swan, W., 2007. Building trust in construction projects. Supply Chain Management: An International Journal, 12 (6), 385-391. 
Kirsilä, J., Hellström, M., Wikström, K., 2007. Integration as a project management concept: A study of the commissioning process in industrial deliveries. International Journal of Project Management, 25 (7), 714-721.

Kotzab, H., Teller, C., Grant, D.B., Sparks, L., 2011. Antecedents for the adoption and execution of supply chain management. Supply Chain Management: An International Journal, 16 (4), 231-245.

Kozek, J., Hebberd, C., 1998. Contracts: share the risk. Journal of Construction Engineering and Management, $1112,356-361$.

Kulatunga, U., Amaratunga, D., Haigh, R., 2007. Performance measurement in the construction research and development. International Journal of Productivity and Performance Management, 56 (8), 673-688.

Leufkens, A.S., Noorderhaven, N.G., 2011. Learning to collaborate in multi-organizational projects. International Journal of Project Management, 29 (4), 432-441.

Linstone, H., Turoff, M., 2002. The Delphi Method: techniques and applications, Addison-Wesley, Reading, MA.

Love, P. E., Irani, Z., Edwards, D. J., 2004. A seamless supply chain management model for construction. Supply chain management: an international journal, 9 (1), 43-56.

Malone, D. W., 1975. An introduction to the application of interpretive structural modeling ISM. International Journal of Operations \& Production Management, 14 (6), 52-59.

Mandal, A. and Deshmukh, S.G. 1994. Vendor selection using interpretive structural modeling ISM. International Journal of Operations \& Production Management, 14 (6), 52-59.

Meng, X., Gallagher, B., 2012. The impact of incentive mechanisms on project performance. International Journal of Project Management, 30 (3), 352-362. 
Maleki, M. and Cruz-Machado, V. 2015. Integration of practices and customer values in a supply chain, International Journal of Management Science and Engineering Management, vol 10, no1, pages 9-19

Mitchell, V., McGoldrick, P., 1994. The role of geodemographics in segmenting and targeting consumer markets: a Delphi study. European Journal of Marketing, 28, 54-72.

Ng, T., Rose, T., Mak, M., Chen, S.E., 2002. Problematic issues associated with project partnering the contractor perspective. International Journal of Project Management, 20 (6), 437-449.

Nikas, A., Poulymenakou, A., Kriaris, P., 2006, Investigating antecedents and drivers affecting the adoption of collaboration technologies in the construction industry, Automation in Construction, 16 (5), pp. 632-641.

O’Brien, W.J., 2000. Implementation issues in project web sites: a practitioner's viewpoint. Journal of Management in Engineering, May/June, 34-39.

O’Brien, W. J., London, K., Vrijhoef, R. 2002. Construction supply chain modeling: a research review and interdisciplinary research agenda. InProceedings IGLC 10, 1-19.

Olsen, T. E., Osmundsen, P., 2005. Sharing of endogenous risk in construction. Journal of Economic Behavior and Organization, 58 (4), 511-526.

Palaneeswaran, E., Kumaraswamy, M. M., Rahman, M., Ng, T., 2003. Curing congenital construction industry disorders through relationally integrated supply chains. Building and Environment, 38, 571-582.

Pesämaa, O., Eriksson, P. E., Hair, J. F., 2009. Validating a model of cooperative procurement in the construction industry. International Journal of Project Management, 27 (6), 552-559.

Samaddar S., Nargundkar, S., Daley, M., 2006. Inter-organizational information sharing: The role of supply network configuration and partner goal congruence. European Journal of Operational Research, 174 (2), 744-765. 
Skinner, W., 1969. Manufacturing-missing link in corporate strategy. Harvard Business Review, May/June.

Smyth, H., Gustafsson, M., Ganskau, E., 2010. The value of trust in project business. International Journal of Project Management, 28 (2), 117-129.

Söderlund, J., 2004. On the broadening scope of the research on projects: a review and a model for analysis. International Journal of Project Management, 22, 655-67.

Stock, J. R:, Boyer, S. L., Harmon, T., 2010. Research opportunities in supply chain management, Journal of the Academy of Marketing Science, 38 (1), 32-41.

Thakkar J., Kanda, A., Deshmukh, S. G., 2008. Interpretive structural modeling (ISM) of ITenablers for Indian manufacturing SMEs. Inf. Manag. Comput. Security, 16 (2), 113-136.

Tserng, H.P., Lin, P.H., 2002. An accelerated subcontracting and procuring model for construction projects. Automation in Construction, 11, 105-125.

Turner, J.R., Müller, R., 2003. On the nature of the project as a temporary organization. International Journal of Project Management, 21 (1), 1-8.

Vrijhoef, R., Koskela L., 2000. The four roles of supply chain management in construction. European Journal of Purchasing \& Supply Management, 6, 169-178.

Xue, X., Wang, Y., Shen, Q., Li, X., 2005. An agent-based framework for supply chain coordination in construction. Automation in Construction, 14, 413-430.

Xue, X., Wang, Y., Shen, Q., Yu, X., 2007. Coordination mechanisms for construction supply chain management in the Internet environment. International Journal of Project Management, 25 (2), 150 157.

Xue, X., Shen, Q., Tan, Y., Zhang, Y., Fan, H., 2011. Comparing the value of information sharing under different inventory policies in construction supply chain. International Journal of Project Management, 29 (7), 867-876. 
Yin, R., 2003. Case Study Research: Design and Methods, $3^{\text {rd }}$ ed., Sage, London.

Young, R., Jordan, E., 2008. Top management support: Mantra or necessity?. International Journal of Project Management, 26 (7), 713-725.

Voss, C., Frohlich, N., Tsikriktsis, M., 2002. Case research in operations management, International Journal of Operations \& Production Management, 22 (2), 195-219.

Walker, D.H.T., Hampson, K.D., 2003. Procurement Strategies: A Relationship-Based Approach, Blackwell Science, Oxford.

Warfield, J. W., 1974. Developing interconnected matrices in structural modeling. IEEE Transcript on Systems Men and Cybernetics, 4 (1), 51-81.

Zaghloul, R., Hartman, F., 2003. Construction contracts: the cost of mistrust. International Journal of Project Management, 21 (6), 419-424. 
Phase 1

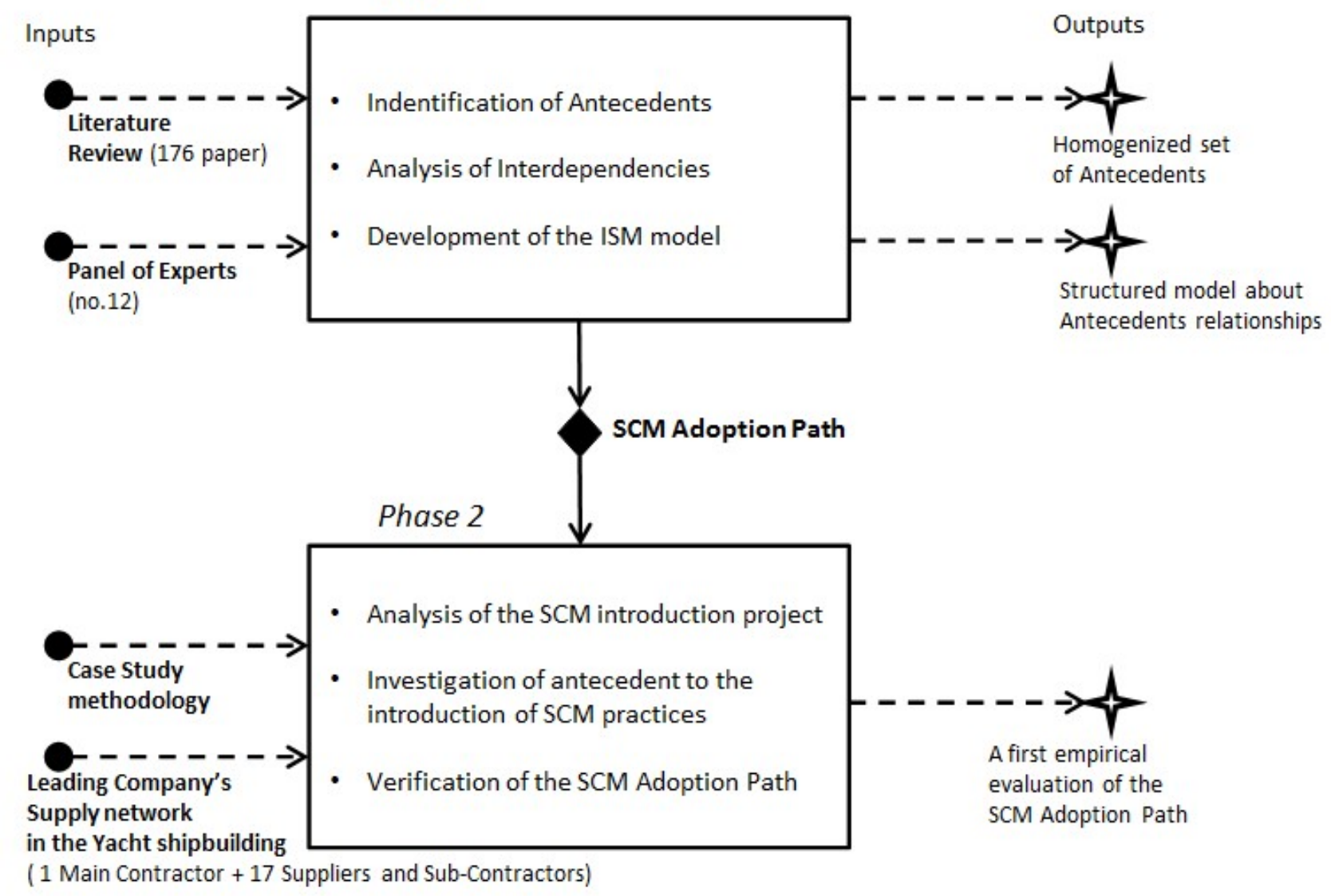

Figure 1 - Research Framework 


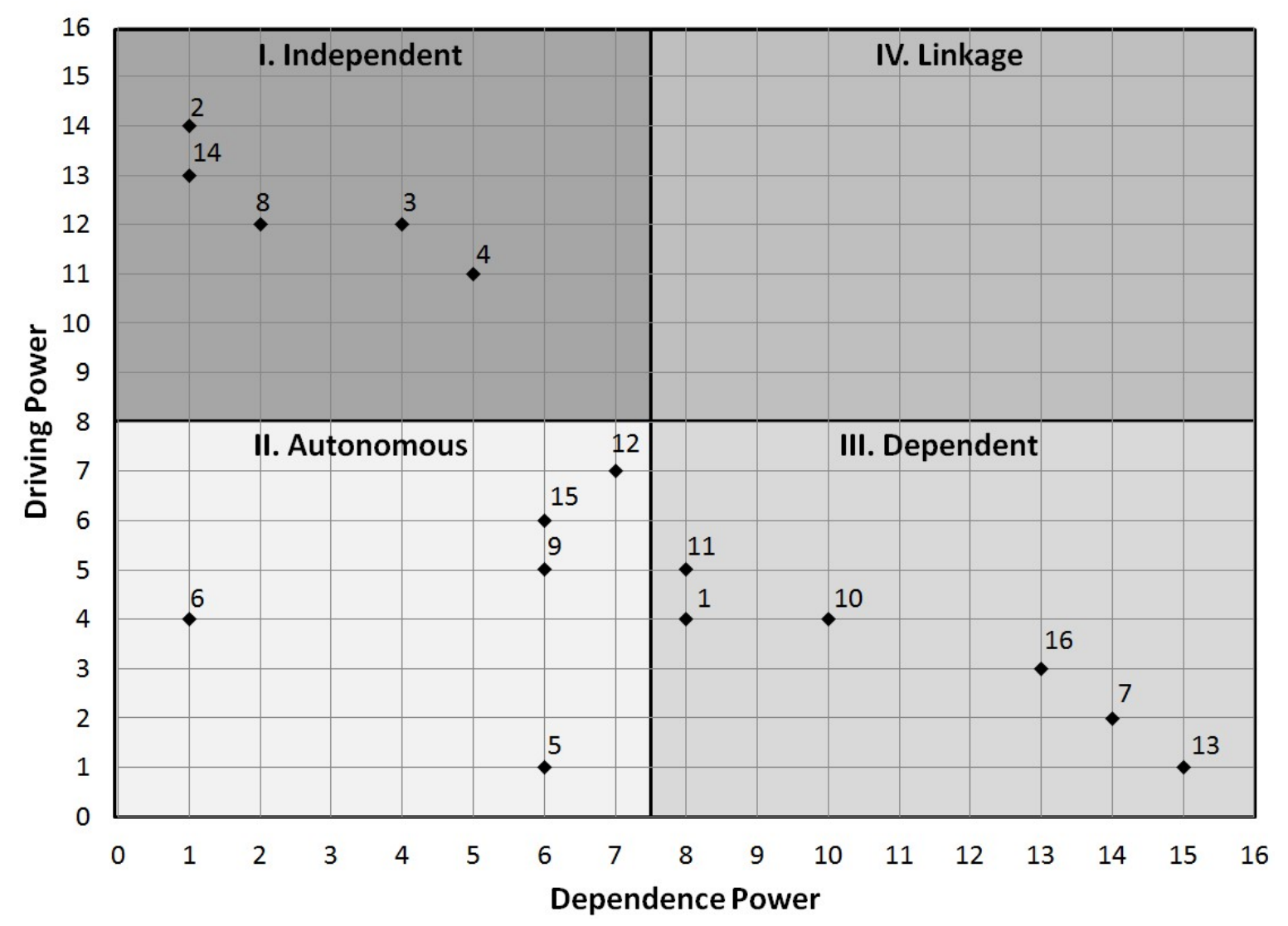

Figure 2 - Power-dependence matrix 


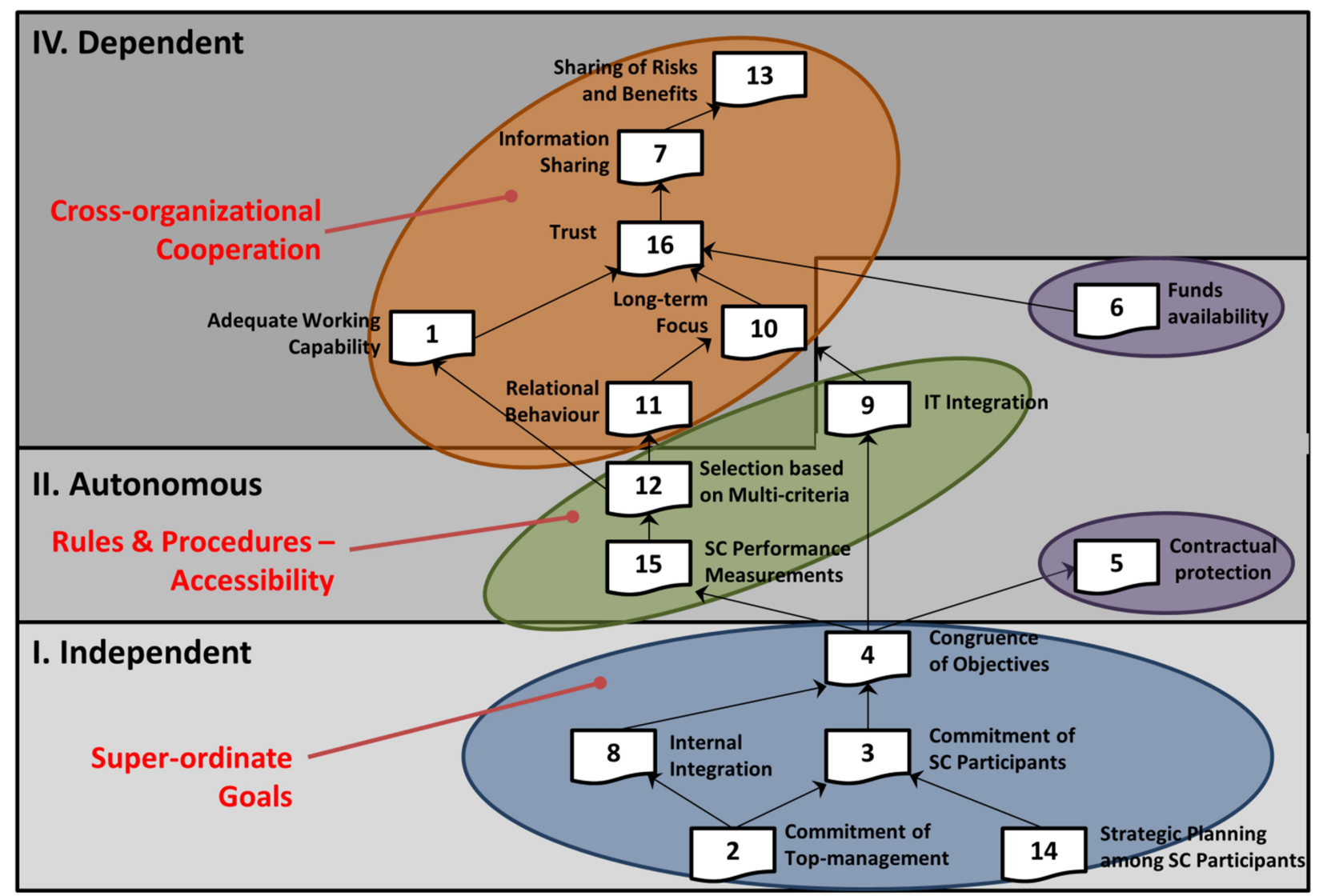

Figure 3 - Final ISM model 


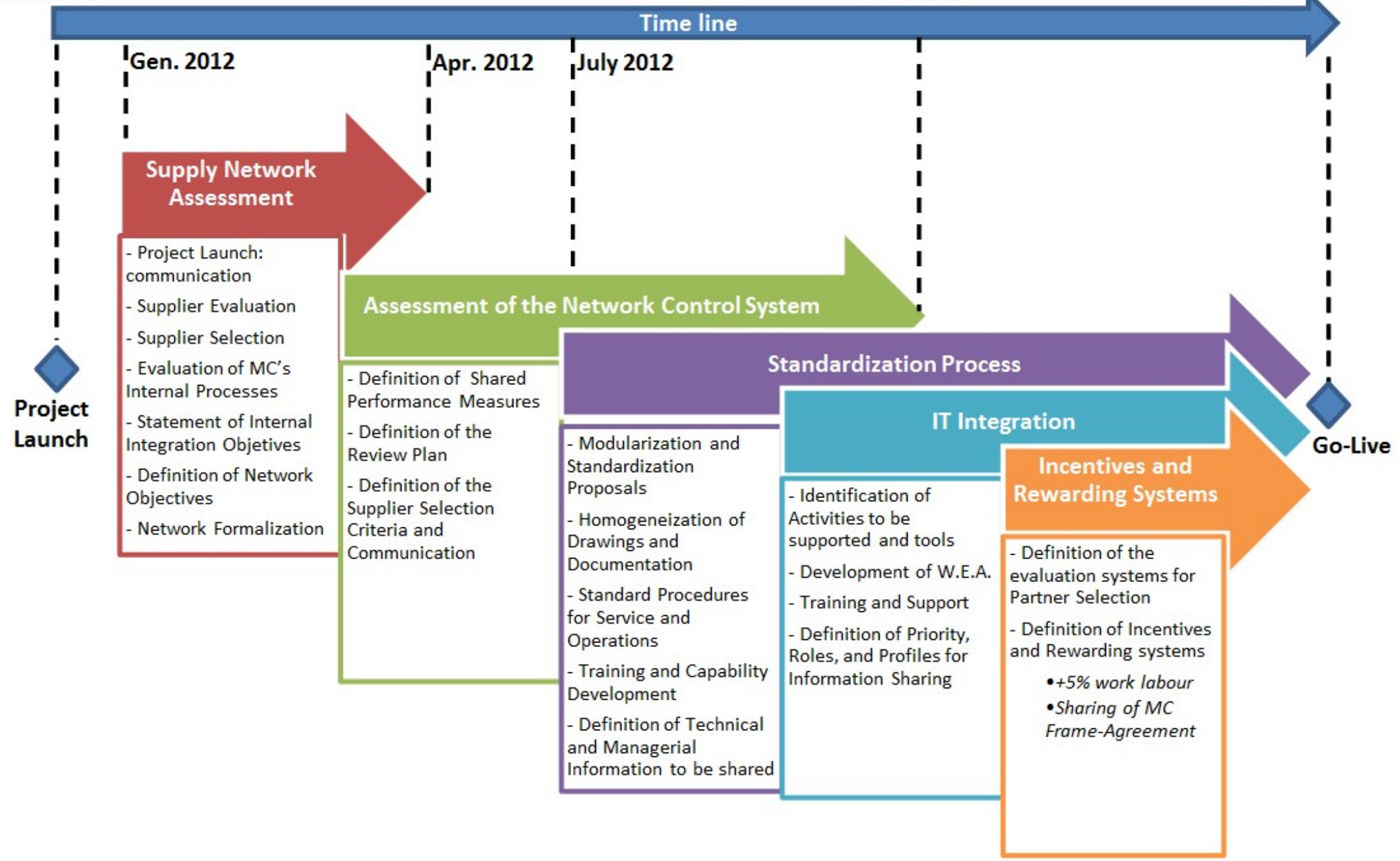




\begin{tabular}{|c|c|c|c|}
\hline Case Company & Role in the Supply Chain & $\begin{array}{l}\text { Company Size (\# } \\
\text { employees) }\end{array}$ & Respondents \\
\hline Company A & Main Contractor & $>1.000$ & $\begin{array}{l}\text { Site Director } \\
\text { Technical Office Director }\end{array}$ \\
\hline Company G & Sub-contractor (Interior Design) & $>50$ & $\mathrm{CEO}$ \\
\hline Company $\mathrm{H}$ & Sub-contractor (Interior Design) & $>50$ & Technical Director \\
\hline Company I & Sub-contractor (Internal Design) & $>50$ & CEO \\
\hline Company J & Supplier (Electrical System) & $>500$ & Production Director \\
\hline Company K & Supplier (Electrical System) & $>50$ & $\mathrm{CEO}$ \\
\hline Company L & Sub-contractor (Electrical System) & $>50$ & $\mathrm{CEO}$ \\
\hline Company M & Sub-contractor (Hull) & $<25$ & $\mathrm{CEO}$ \\
\hline Company N & Sub-contractor (Hull) & $<25$ & CEO \\
\hline Company $\mathrm{O}$ & Sub-contractor (Hull) & $<25$ & $\mathrm{CEO}$ \\
\hline Company P & Sub-contractor (Pipes) & $25-50$ & CEO \\
\hline Company Q & Supplier (Pipes) & $50-100$ & Technical Director \\
\hline Company R & $\begin{array}{l}\text { Sub-contractor (Technical } \\
\text { Preparation) }\end{array}$ & $25-50$ & Project Manager \\
\hline Company S & $\begin{array}{l}\text { Sub-contractor (Technical } \\
\text { Preparation) }\end{array}$ & $25-50$ & $\mathrm{CEO}$ \\
\hline Company T & Supplier (HVAC) & $100-250$ & Production Director \\
\hline Company U & Supplier (HVAC) & $100-250$ & Technical Director \\
\hline Company V & Sub-contractor (Painting) & $50-100$ & Production Director \\
\hline Company X & Sub-contractor (Painting) & $25-50$ & CEO \\
\hline
\end{tabular}

Table 1 - Description of companies and informants of the longitudinal case study 
2 Commitment of top- It is a multidimensional element that offers sustainable competitive advantage in the long-term. It involves the identification of most $\begin{array}{ll}\text { management } & \text { strategic areas for the organization, the resolution of conflicts among internal functions and the support to review plans and to follow up } \\ \text { on results. Reviewing extant literature, top-management commitment has been reported as the most important antecedent to a successful }\end{array}$ project implementation and its absence has been identified as the biggest barrier to implement successful relationships with other SC actors.

3 Commitment of SC participants

for the motivations and the energy necessary to the SCM approach, which introduction represents an element of discomfort and risk for project companies. Commitment among project stakeholders is an important precondition to ensure the competitive advantage of a greater individual effort for all the subjects involved.

\section{Congruence of} objectives

\section{$5 \quad$ Contractua} protection

It is the extent to which SC participants have congruent goals about the introduction of SCM. It refers to the endorsement of common values and beliefs between project actors in order to promote a collective mind and obtain an active participation of users. A unified vision represents a fundamental integrating mechanism that creates a common group identity and encourages a mutual acceptance of the SCM concept among project companies.

It is frequently used in the project environment to rigorously delineate relational terms and conditions. A proper use of contract clauses would result in significant savings for project companies, improving the risk management process through the assessment and the would result in significant savings for projec
minimization of relational controversies.

It influences collaborative decisions and even compromise organizations' survival. The SCM approach can be undermined by financial issues, particularly in respect of late payments that may compromise the financial stability of smaller organizations. The minimization of possible threats related to fund shortages is fundamental to successfully implement supply chain relationships, especially during the negotiation process.

It should drive all the project phases and, thus, enhance the competitiveness of the whole SC. The role of information assumes a critica and strategic connotation for project supply chains, which are essentially information transaction processes. Information sharing is required to make correct decision in time at both firm- and SC-level. It is influenced by the acquisition, the processing and the transfer practices within the $\mathrm{SC}$ and the understanding of such practices represents the first step to manage information as a strategic resource.

It includes a technical and a social dimension that are required to implement SCM efforts within teams and functional departments. The actors within organisational departments need to integrate their activities in order to enhance flexibility, adaptation and coordination during project execution. In particular, integration efforts in the early phases of project life-cycle facilitates joint problem-solving, improves feasibility, and reduces reworks activities.

It is related to the effective data exchange at every project stage between SC participants. Information Technology integration impacts on both technical and managerial side and can provide relevant improvements in the effectiveness and efficiency of designing and managing projects. In particular, emerging ICT provides impressive opportunities to innovate project management practices, by exploiting the projects. In particular, emerging ICT provides impressive opportunities to innovate project management practices, by exploiting the
increased computational power and the benefits of web-based paradigm, such as continuous access to information, minimal software increased computational power and the benefits of web-based paradigm, such as continuous access to information, minimal software
requirements and ease of use. Such IT-tools represent a powerful driver to improve information sharing and communication across the requirements and ease of use. Such IT-tools represent a powerful driver to improve information sharing and communication across
multitude of SC participants but the achievement of expected benefits requires first of all the minimization of the IT gap between multitude of SC participants but the achiever
General Contractors and sub-contractors.

Long-term orientation is important to maximise the resource utilization of most important SC participants and to achieve specific SCM objectives, such as improved quality and flexibility of operations. It requires a combined effort from all parties involved and is fundamental for complex project with a multi-year execution. Long-term focus can provide higher value of cooperation in project team and better exploration/exploitation of knowledge.
Brady and Davis (2004); Bredi (2008); Kulatunga et al. (2007)

Akintoye et al. (2000); Beath, (1991); Young and Jordan (2008)

Burgess and Turner (2000); Eriksson and Nilsson (2008); Guth and Macmillan (1986); Ng et al. (2002)

Crespin-Mazet and Ghauri, (2007); Hsu et al. (2011); Samaddar et al. (2006)

Khalfan et al. (2001); Kozek and Hebberd (1998); Palaneeswaran et al. (2003); Zaghloul and Hartman (2003)

Briscoe et al. (2001); Tserng and Lin (2002)

Edum-Fotwe et al. (2001); Xue et al. (2011)

Baiden and Price (2011); Eriksson (2012); Errasti et al. (2009) Kirsilä et al. (2007)

Ahuja et al. (2009); Briscoe et a (2001); Froese (2010); O'Brien (2000)

Chen and Chen (2007); Ingirige and Sexton (2006): Walker and Hampson (2003) 
2 Selection based on It involves the procurement mechanisms to assess the resources and the capabilities of SC participants. Such mechanisms enable market multi-criteria

responsiveness by avoiding, at the same time, quality deficiencies and poor customer satisfaction during project execution. Hence, risks and uncertainty can be reduced by selecting the suitable subcontractor for each project activity. Selection criteria should include the join occurrence of relational ability, technical competence and economic-based attributes.

13 Sharing of risks and

It incentives to widespread the awareness of SCM adoption. Risks and benefits of SCM need to be identified and managed in order to effectively and efficiently organize the supply network. In particular, incentive-based systems are necessary to motivate actors to implement a resource intensive approach such as SCM by rewarding innovative and effective solutions. The incentive-based perspective is intensely related with the management of risks. For complex projects, General Contractors can affect the level of risk by shifting it to the subcontractors in exchange of a higher construction cost. At this purpose, the balance of this trade-off requires a detailed classification of project risk factors in order to support managers in achieving a more efficient use of company's limited resources.

14 Strategic planning among SC participants

It refers to their ability to undertake strategic directions, by providing sound basis to introduce SCM approach. Most of project activities are performed by Small Medium Enterprises (SMEs), which are responsible for their successful execution and for the management of material suppliers. Therefore, the implementation of SCM principles have to be extended beyond General Contractors' organizational boundaries to reach other SC participants, which require effective project planning to achieve high value generation.

15 SC performance

It includes the proper settlement and monitoring of indicators for a multiple interdependent objective system with a supply chain measurements perspective. The focus on overall performance reduces sub-optimizations by providing feedback for future projects and by defining clear (improvement of financial performance

Gadde and Dubois (2010); Hartmann and Caerteling (2010) Pesämaa et al. (2009)

Aloini et al. (2012); Meng and
Gallagher (2012); Olsen and Gallagher (2012); Olsen and Osmundsen (2005) for the General Contractor. SC performance can be evaluated through various techniques, such as simple weighted rating or more complex fuzzy hybrid neural network.

16 Trust It is related to the levels of faith, reliance, and confidence in other SC participants. Project-based industries represent a "small world" and reputation is considered an important intangible asset. Trust has been identified as one of the most important factors to modernize complex and highly fragmented project industries. Also, high levels of trust among SC members can improve project SC performance and can be built only with the willingness to adapt to the changing and uncertain conditions of the project environment.

Errasti et al. (2007); Fernie and Thorpe (2007); Gunasekaran an Love (1998); Söderlund (2004)

Chen (2011); Cheng et al. (2011); Ekström et al. (2003); Kulatunga et al. (2007)

Kadefors (2004); Khalfan et al. (2007); Smyth et al. (2010)

\section{Table 2 - Antecedents of SCM approaches in the yacht industry}




\begin{tabular}{|c|c|c|c|c|c|c|c|c|c|c|c|c|c|c|c|c|}
\hline \multicolumn{2}{|c|}{ Antecedents } & 16 & 15 & 14 & 13 & 12 & 11 & 10 & 9 & 8 & 7 & 6 & 5 & 4 & 3 & 2 \\
\hline 1 & Adequate working capabilities & $\mathrm{D}$ & $\mathrm{R}$ & $\mathrm{R}$ & $\mathrm{D}$ & $\mathrm{R}$ & $\mathrm{U}$ & $\mathrm{U}$ & $\mathrm{U}$ & $\mathrm{U}$ & $\mathrm{U}$ & $\mathrm{U}$ & $\mathrm{U}$ & $\mathrm{R}$ & $\mathrm{R}$ & $\mathrm{R}$ \\
\hline 2 & Commitment of top-management & $\mathrm{U}$ & $\mathrm{D}$ & $\mathrm{U}$ & $\mathrm{D}$ & $\mathrm{D}$ & $\mathrm{D}$ & $\mathrm{D}$ & $\mathrm{D}$ & $\mathrm{D}$ & $\mathrm{U}$ & $\mathrm{U}$ & $\mathrm{D}$ & $\mathrm{D}$ & $\mathrm{D}$ & \\
\hline 3 & Commitment of SC participants & $\mathrm{U}$ & $\mathrm{D}$ & $\mathrm{R}$ & $\mathrm{D}$ & $\mathrm{D}$ & $\mathrm{D}$ & $\mathrm{D}$ & $\mathrm{D}$ & $\mathrm{U}$ & $\mathrm{U}$ & $\mathrm{U}$ & $\mathrm{D}$ & $\mathrm{D}$ & & \\
\hline 4 & Congruence of objectives & $\mathrm{D}$ & $\mathrm{D}$ & $\mathrm{R}$ & $\mathrm{D}$ & $\mathrm{D}$ & $\mathrm{D}$ & $\mathrm{D}$ & $\mathrm{D}$ & $\mathrm{R}$ & $\mathrm{D}$ & $\mathrm{U}$ & $\mathrm{D}$ & & & \\
\hline 5 & Contractual protection & $\mathrm{U}$ & $\mathrm{U}$ & $\mathrm{R}$ & $\mathrm{U}$ & $\mathrm{U}$ & $\mathrm{U}$ & $\mathrm{U}$ & $\mathrm{U}$ & $\mathrm{U}$ & $\mathrm{U}$ & $\mathrm{U}$ & & & & \\
\hline 6 & Financial stability & $\mathrm{D}$ & $\mathrm{U}$ & $\mathrm{U}$ & $\mathrm{D}$ & $\mathrm{U}$ & $\mathrm{U}$ & $\mathrm{U}$ & $\mathrm{U}$ & $\mathrm{U}$ & $\mathrm{U}$ & & & & & \\
\hline 7 & Information sharing & $\mathrm{R}$ & $\mathrm{U}$ & $\mathrm{R}$ & $\mathrm{D}$ & $\mathrm{U}$ & $\mathrm{R}$ & $\mathrm{R}$ & $\mathrm{R}$ & $\mathrm{U}$ & & & & & & \\
\hline 8 & Internal integration & $\mathrm{U}$ & $\mathrm{U}$ & $\mathrm{U}$ & $\mathrm{D}$ & $\mathrm{U}$ & $\mathrm{D}$ & $\mathrm{U}$ & $\mathrm{D}$ & & & & & & & \\
\hline 9 & IT integration & $\mathrm{U}$ & $\mathrm{U}$ & $\mathrm{U}$ & $\mathrm{D}$ & $\mathrm{U}$ & $\mathrm{U}$ & $\mathrm{D}$ & & & & & & & & \\
\hline 10 & Long-term focus & $\mathrm{D}$ & $\mathrm{R}$ & $\mathrm{R}$ & $\mathrm{D}$ & $\mathrm{R}$ & $\mathrm{R}$ & & & & & & & & & \\
\hline 11 & Relational behaviour & $\mathrm{D}$ & $\mathrm{R}$ & $\mathrm{R}$ & $\mathrm{D}$ & $\mathrm{R}$ & & & & & & & & & & \\
\hline 12 & Selection based on multi-criteria & $\mathrm{U}$ & $\mathrm{R}$ & $\mathrm{U}$ & $\mathrm{D}$ & & & & & & & & & & & \\
\hline 13 & Sharing of risks and benefits & $\mathrm{R}$ & $\mathrm{R}$ & $\mathrm{R}$ & & & & & & & & & & & & \\
\hline 14 & $\begin{array}{l}\text { Strategic planning among SC } \\
\text { participants }\end{array}$ & $\mathrm{U}$ & $\mathrm{D}$ & & & & & & & & & & & & & \\
\hline 15 & SC performance measurements & $\mathrm{D}$ & & & & & & & & & & & & & & \\
\hline 16 & Trust & & & & & & & & & & & & & & & \\
\hline
\end{tabular}

Table 3 - Structural Self-Interaction Matrix (SSIM) 


\begin{tabular}{|c|c|c|c|c|c|c|c|c|c|c|c|c|c|c|c|c|c|c|}
\hline \multicolumn{2}{|c|}{ Antecedents } & \multirow{2}{*}{$\begin{array}{l}1 \\
1\end{array}$} & \multirow{2}{*}{$\begin{array}{l}2 \\
0\end{array}$} & \multirow{2}{*}{$\begin{array}{l}3 \\
0\end{array}$} & \multirow{2}{*}{$\begin{array}{l}4 \\
0\end{array}$} & \multirow{2}{*}{$\begin{array}{l}5 \\
0\end{array}$} & \multirow{2}{*}{$\begin{array}{l}6 \\
0\end{array}$} & \multirow{2}{*}{$\begin{array}{l}7 \\
1\end{array}$} & \multirow{2}{*}{$\begin{array}{l}8 \\
0\end{array}$} & \multirow{2}{*}{$\begin{array}{l}9 \\
0\end{array}$} & \multirow{2}{*}{$\begin{array}{l}\mathbf{1 0} \\
0\end{array}$} & \multirow{2}{*}{$\begin{array}{l}11 \\
0\end{array}$} & \multirow{2}{*}{$\begin{array}{l}12 \\
0\end{array}$} & \multirow{2}{*}{$\begin{array}{l}13 \\
1\end{array}$} & \multirow{2}{*}{$\begin{array}{l}14 \\
0\end{array}$} & \multirow{2}{*}{$\begin{array}{l}15 \\
0\end{array}$} & \multirow{2}{*}{$\begin{array}{l}16 \\
1\end{array}$} & \multirow{2}{*}{$\begin{array}{l}\text { Driving Power } \\
4\end{array}$} \\
\hline 1 & Adequate working capabilities & & & & & & & & & & & & & & & & & \\
\hline 2 & $\begin{array}{l}\text { Commitment of top- } \\
\text { management }\end{array}$ & 1 & 1 & 1 & 1 & 1 & 0 & 1 & 1 & 1 & 1 & 1 & 1 & 1 & 0 & 1 & 1 & 14 \\
\hline 3 & $\begin{array}{l}\text { Commitment of SC } \\
\text { participants }\end{array}$ & 1 & 0 & 1 & 1 & 1 & 0 & 1 & 0 & 1 & 1 & 1 & 1 & 1 & 0 & 1 & 1 & 12 \\
\hline 4 & Congruence of objectives & 1 & 0 & 0 & 1 & 1 & 0 & 1 & 0 & 1 & 1 & 1 & 1 & 1 & 0 & 1 & 1 & 11 \\
\hline 5 & Contractual protection & 0 & 0 & 0 & 0 & 1 & 0 & 0 & 0 & 0 & 0 & 0 & 0 & 0 & 0 & 0 & 0 & 1 \\
\hline 6 & Funds availability & 0 & 0 & 0 & 0 & 0 & 1 & 1 & 0 & 0 & 0 & 0 & 0 & 1 & 0 & 0 & 1 & 4 \\
\hline 7 & Information sharing & 0 & 0 & 0 & 0 & 0 & 0 & 1 & 0 & 0 & 0 & 0 & 0 & 1 & 0 & 0 & 0 & 2 \\
\hline 8 & Internal integration & 1 & 0 & 0 & 1 & 1 & 0 & 1 & 1 & 1 & 1 & 1 & 1 & 1 & 0 & 1 & 1 & 12 \\
\hline 9 & IT integration & 0 & 0 & 0 & 0 & 0 & 0 & 1 & 0 & 1 & 1 & 0 & 0 & 1 & 0 & 0 & 1 & 5 \\
\hline 10 & Long-term focus & 0 & 0 & 0 & 0 & 0 & 0 & 1 & 0 & 0 & 1 & 0 & 0 & 1 & 0 & 0 & 1 & 4 \\
\hline 11 & Relational behaviour & 0 & 0 & 0 & 0 & 0 & 0 & 1 & 0 & 0 & 1 & 1 & 0 & 1 & 0 & 0 & 1 & 5 \\
\hline 12 & $\begin{array}{l}\text { Selection based on multi- } \\
\text { criteria }\end{array}$ & 1 & 0 & 0 & 0 & 0 & 0 & 1 & 0 & 0 & 1 & 1 & 1 & 1 & 0 & 0 & 1 & 7 \\
\hline 13 & Sharing of risks and benefits & 0 & 0 & 0 & 0 & 0 & 0 & 0 & 0 & 0 & 0 & 0 & 0 & 1 & 0 & 0 & 0 & 1 \\
\hline 14 & $\begin{array}{l}\text { Strategic planning among SC } \\
\text { participants }\end{array}$ & 1 & 0 & 1 & 1 & 1 & 0 & 1 & 0 & 1 & 1 & 1 & 1 & 1 & 1 & 1 & 1 & 13 \\
\hline 15 & $\begin{array}{l}\text { SC performance } \\
\text { measurements }\end{array}$ & 1 & 0 & 0 & 0 & 0 & 0 & 1 & 0 & 0 & 1 & 1 & 1 & 1 & 0 & 1 & 1 & 6 \\
\hline 16 & Trust & 0 & 0 & 0 & 0 & 0 & 0 & 1 & 0 & 0 & 0 & 0 & 0 & 1 & 0 & 0 & 1 & 3 \\
\hline & Dependence power & 8 & 1 & 4 & 5 & 6 & 1 & 14 & 2 & 6 & 10 & 8 & 7 & 15 & 1 & 6 & 13 & \\
\hline
\end{tabular}

Table 4 - Final Reachability Matrix (RM) 


\begin{tabular}{cllll}
\hline Antecedent & Lower level Antecedent set & Reachability set & $1,7,13,16$ & Intersection set \\
$\mathbf{1}$ & $\begin{array}{l}\text { Adequate working } \\
\text { capabilities }\end{array}$ & $1,2,4,8,10,12,14,15$ & 1 & \\
$\mathbf{2}$ & $\begin{array}{l}\text { Commitment of top- } \\
\text { management }\end{array}$ & 2 & $1,2,3,4,5,7,8,9,10,11,12,13,15,16$ & 2 \\
$\mathbf{3}$ & $\begin{array}{l}\text { Commitment of SC } \\
\text { participants }\end{array}$ & $1,3,4,5,7,9,10,11,12,13,15,16$ & 3 \\
$\mathbf{4}$ & Congruence of objectives & $2,3,14,4,8,14$ & $1,4,5,7,9,10,11,12,13,15,16$ & 4 \\
$\mathbf{5}$ & Contractual protection & $2,3,4,5,8,13,14$ & 5 & 5 \\
$\mathbf{6}$ & Funds availability & 6 & $6,7,13,16$ & 6 \\
$\mathbf{7}$ & Information sharing & $1,2,3,4,6,7,8,9,10,11,12,14,15$ & 7,13 & 7 \\
$\mathbf{8}$ & Internal integration & 2,8 & $1,4,5,7,8,9,10,11,12,13,15,16$ & 8 \\
$\mathbf{9}$ & IT integration & $2,3,4,8,9,14$ & $7,9,10,13,16$ & 9 \\
$\mathbf{1 0}$ & Long-term focus & $2,3,4,8,9,10,11,14$ & $7,10,13,16$ & 10 \\
$\mathbf{1 1}$ & Relational behaviour & $2,3,4,8,11,12,14,15$ & $7,10,11,13,16$ & 11 \\
$\mathbf{1 2}$ & $\begin{array}{l}\text { Selection based on multi- } \\
\text { criteria }\end{array}$ & $2,3,4,8,12,14,15$ & $1,7,10,11,12,13,16$ & 12 \\
$\mathbf{1 3}$ & Sharing of risks and & $1,2,3,4,6,7,8,9,10,11,12,13,14,15$, & 13 & 14 \\
& benefits & 16 & & 13 \\
$\mathbf{1 4}$ & Strategic planning among & 14 & $1,3,4,5,7,9,10,11,12,13,14,15,16$ & 14 \\
& SC participants & & $1,7,10,12,13,15,16$ & 16 \\
$\mathbf{1 5}$ & $\begin{array}{l}\text { SC performance } \\
\text { measurements }\end{array}$ & $2,3,4,8,14,15$ & & \\
$\mathbf{1 6}$ & Trust & $1,2,3,4,6,8,9,10,11,14,15,16$ & $7,13,16$ & \\
\hline
\end{tabular}

Table 5 - First iteration of level partitioning 